\title{
Development, growth and dry matter partitioning in bambara groundnut (Vigna subterranea) as influenced by photoperiod and shading
}

\author{
M. BRINK \\ Department of Crop Science, Wageningen Agricultural University, Haarweg 333, 6709 RZ Wageningen, \\ The Netherlands
}

(Revised MS received 30 March 1999)

\begin{abstract}
SUMMARY
A semi-controlled environment study was conducted from May to September 1996 in Wageningen, The Netherlands, to investigate the interaction between growth and development in bambara groundnut (Vigna subterranea) and the influence of photoperiod on dry matter partitioning. The experimental design was a split-plot with four photoperiods $(10 \cdot 5,11 \cdot 8,13 \cdot 2$ and $14 \cdot 5 \mathrm{~h} / \mathrm{d})$ and two light treatments: unshaded and shaded (42\% light reduction). The selection used was 'DipC94' from Botswana. The dates of $50 \%$ flowering and $50 \%$ podding were determined, and samples of plants were harvested at 22, 36, 50, 64, 78, 92, 106 and 120 days after sowing. Total dry matter production was $41 \%$ lower in the shaded treatment than in the unshaded treatment, but the rates of progress from sowing to flowering and flowering to podding decreased by only 3 and $12 \%$ respectively. This suggests that growth and development in bambara groundnut are largely independent. Photoperiod influenced dry matter partitioning indirectly, through its influence on the onset of podding. There were, however, no strong direct photoperiod effects on dry matter partitioning, either before or after the onset of podding.
\end{abstract}

\section{INTRODUCTION}

The leguminous crop bambara groundnut (Vigna subterranea (L.) Verdc.) is an important secondary food crop in Africa, mainly grown by smallholders in drier regions (Linnemann \& Azam-Ali 1993). Bambara groundnut is an indeterminate annual herb, with creeping stems carrying trifoliate leaves with erect petioles. Flowers are formed at the base of the petioles, usually in pairs. After pollination, the peduncle grows out and pods form on or under the ground. The pods usually contain one seed. Unripe and ripe seeds are used for human consumption (Linnemann \& Azam-Ali 1993).

It is generally assumed that photoperiod and temperature are the main environmental factors influencing reproductive development in annual crops (Hodges 1991; Sinclair et al. 1991; Summerfield et al. 1991). In most bambara groundnut genotypes investigated, the onset of flowering is photoperiod-insensitive and the onset of podding is retarded by long

\footnotetext{
* Present address: PROSEA Publication Office, P.O. Box 341, 6700 AH Wageningen, The Netherlands. Email: Martin.Brink@PROS.AGRO.WAU.NL
}

photoperiods (Linnemann 1994; Brink 1997). The effects of photoperiod and temperature on rates of progress from sowing to flowering and flowering to podding have been quantified in the form of linear models for different bambara groundnut selections, using data from semi-controlled environment research (Brink 1997). These models are based on the widely held assumption that interaction between development and growth may be ignored and that crop development may be modelled separately from crop growth.

Another common assumption in crop growth modelling is that dry matter (DM) partitioning depends mainly on development stage and is not directly influenced by photoperiod. In bambara groundnut, photoperiod influences DM partitioning indirectly through its influence on reproductive development. The onset of podding coincides with a major shift in the assimilate distribution, which becomes directed mainly towards pod growth (Linnemann et al. 1995). Linnemann et al. (1995) suggested that the partitioning factors before this major switch from vegetative to pod growth may not be constant, but directly influenced by photoperiod. They found that the percentage of above ground 
matter partitioned to the leaf blades of selection 'Tiga Nicuru' was greater under short (10 or $12 \mathrm{~h} / \mathrm{d}$ ) than under long $(14$ or $16 \mathrm{~h} / \mathrm{d})$ photoperiods and the percentage partitioned to the stem parts (petioles and stems) smaller. They also suggested that the partitioning factors after the onset of podding are directly influenced by photoperiod, because the pod growth rate in selection 'Ankpa4' was higher under a $10 \mathrm{~h} / \mathrm{d}$ photoperiod than under a $12 \mathrm{~h} / \mathrm{d}$ photoperiod. In soyabean (Glycine max (L.) Merr.), the proportion of $\mathrm{DM}$ increase partitioned to the reproductive structures after pod set has also been found to be much greater under short days than under long days or treatment with interrupted nights (Cure et al. 1982; Morandi et al. 1988).

The two objectives of the present study on bambara groundnut were therefore to find out if there is any interaction between growth and development and whether photoperiod has a direct effect on DM partitioning.

\section{MATERIALS AND METHODS}

A semi-controlled environment experiment was conducted in the period 26 May to 23 September 1996 in Wageningen, The Netherlands $\left(51^{\circ} 58^{\prime} \mathrm{N}\right)$. The experimental design was a split-plot with photoperiod as the main factor and shading as the split factor, and two replicates. The experiment was carried out in two identical glasshouses with forced ventilation, which functioned as replicates.

A tent with four compartments was placed in each glasshouse, which made it possible to apply four different photoperiods. From 08.00 to $16.00 \mathrm{~h}$, the tents were removed and the plants received natural daylight. From 16.00 to $08.00 \mathrm{~h}$, the plants were covered by the tents, and the photoperiod in the compartments was prolonged to a different extent by means of low intensity artificial light (four Philips TLD $36 \mathrm{~W}$ fluorescent tubes (colour no. 84) and two $40 \mathrm{~W}$ incandescent bulbs per compartment). This ensured there was little difference in the amount of photosynthetically active radiation (PAR) received in different photoperiods. The constant photoperiods in the four compartments in each glasshouse were 10.5 , $11 \cdot 8,13 \cdot 2$ and $14.5 \mathrm{~h} / \mathrm{d}$. Artificial light was supplied from 07.00 to $08.00 \mathrm{~h}$ and from 16.00 to respectively $17.30,18.50,20.10$ and $21.30 \mathrm{~h}$ for the different photoperiods. Removable metal roofs were put over the glasshouses from 16.00 to $08.00 \mathrm{~h}$, to exclude daylight and to prevent the temperature inside the tents from becoming too high.

Each compartment contained a staging with 80 plants of bambara groundnut selection 'DipC94', a cream coloured selection collected from a farmer at Diphiri, near Gaborone, Botswana $\left(24^{\circ} 40^{\prime} \mathrm{S}\right.$; $25^{\circ} 55^{\prime} \mathrm{E}$ ). One half of each table (40 plants) was covered from 08.00 to $16.00 \mathrm{~h}$ with a frame of green shade netting. The nets were removed from 16.00 to $08.00 \mathrm{~h}$, and both halves of each table received the same low intensity artificial light. To estimate the light reduction by the glasshouse structure and the shading treatment, ceptometer measurements were carried out five times: in the morning and in the afternoon at the beginning and at the end of the experimental period, and in the afternoon in the second half of June, when outside radiation reached a peak. The PAR at plant level in the unshaded treatments was $52 \%$ of that outside the glasshouse. Shade netting caused a further average PAR reduction of $42 \%$. The mean global radiation in the experimental period, measured in a meteorological station at c. $500 \mathrm{~m}$ distance from the glasshouse, was 15.9 $\mathrm{MJ} / \mathrm{m}^{2} / \mathrm{d}$ (Department of Meteorology, Wageningen Agricultural University), which corresponds to c. 8 $\mathrm{MJ} / \mathrm{m}^{2} / \mathrm{d} \mathrm{PAR}$. The radiation between 08.00 and 16.00 was estimated to be $77 \%$ of the daily radiation in the period June-September (Anon. 1989).

From 10.00 to $16.00 \mathrm{~h}$, the temperature in the glasshouse was set at $27^{\circ} \mathrm{C}$; from 18.00 to $08.00 \mathrm{~h}$ at $23^{\circ} \mathrm{C}$. Between 08.00 and $10.00 \mathrm{~h}$ the temperature was set to increase gradually from 23 to $27^{\circ} \mathrm{C}$; from 16.00 to $18.00 \mathrm{~h}$ to decrease gradually from 27 to $23{ }^{\circ} \mathrm{C}$. The average temperature throughout the whole experiment was $25 \cdot 0^{\circ} \mathrm{C}$.

The seeds were pre-germinated in a germination cabinet at $30^{\circ} \mathrm{C}$. When the root tips became visible, the plants were transplanted (one plant per pot) in white plastic 5 litre pots, filled with a $1: 1 \mathrm{v} / \mathrm{v}$ mixture of sand and potting compost (' potting compost no. 4' from Lentse potgrond b.v., consisting of $85 \%$ peat and $15 \%$ clay). There were 22 pots $/ \mathrm{m}^{2}$ from transplanting to the first harvest (22 DAS) and 20 pots $/ \mathrm{m}^{2}$ from the first harvest onwards. At transplanting, Bradyrhizobium strain CB 756, obtained from the Department of Microbiology, Wageningen Agricultural University, was put in the planting hole. The plants were fertilized with a complete nutrient solution obtained by mixing $0.833 \mathrm{~g}$ 'Nutriflora-t' (supplied by Windmill Holland b.v.) and $1 \mathrm{~g}$ calcium nitrate in 1 litre of tap water, resulting in a nutrient content of $172 \mathrm{mg} / 1 \mathrm{~N}, 39 \mathrm{mg} / 1 \mathrm{P}$, and $263 \mathrm{mg} / 1 \mathrm{~K}$. The solution (220 ml per plant) was applied five times at 2-weekly intervals between 24 and 82 days after sowing (DAS). The plants were kept well-watered. Biological pest control was used: Amblyseius cucumeris and Orius insidiosus were introduced regularly against thrips (Frankliniella occidentalis and Thrips tabaci), and Phytoseiulus persimilis against spider mites (Tetranychus urticae). The plants were circulated weekly to minimize the effects of positional variation in the environment. This was done by systematic rearrangement of the pots within each subplot, the subplots within each plot, and the plots within each replicate. The plants were earthed-up individually on the day they had a pod $>0.5 \mathrm{~cm}$ in length. 
Non-destructive observations included dates of onset of flowering and onset of podding of each plant. Flowering onset was defined as the day on which the plant had its first open flower, and podding onset as the first day the plant had a pod at least $0.5 \mathrm{~cm}$ long. Direct podding observations were possible because the selection 'DipC94' forms pods on the soil surface. On the basis of the individual plant observations, the mean dates when $50 \%$ of the plants in a treatment had started flowering (' $50 \%$ flowering'), and $50 \%$ of the plants in a treatment had started podding ( $50 \%$ podding') were determined. Daily counts of open flowers per plant were carried out on six plants per treatment per replicate from the onset of flowering to the onset of podding of these plants.

Eight harvests of five plants per photoperiod/ light combination per replicate were made at 2weekly intervals, from 22 DAS onwards. At each harvest, leaf area, number of leaves and pods, and dry weights of roots, leaf blades, petioles, stems and pods were determined. Fallen plant material was collected throughout the experiment, kept at $4{ }^{\circ} \mathrm{C}$ and dried and weighed at the harvests. Dry matter partitioning factors were calculated by dividing the weight increases of each of the various organs between two successive harvests by the increase in total plant dry weight during the same period. The dry weight of fallen plant material was included in these calculations.

Statistical analysis (analysis of variance) of the results was done with the GENSTAT 5.3 statistical package (Payne et al. 1993).

\section{RESULTS}

\section{Growth}

Total plant dry weight was significantly $(P \leqslant 0.05)$ influenced by shading throughout the experimental period. Interaction effects between photoperiod and shading were never significant $(P>0.05)$, and a significant photoperiod effect was only found at 106
DAS. The final total plant dry weight was $41 \%$ lower in the shaded treatment than in the unshaded treatment (Table 1). The average growth rate over the experimental period was $0.23 \mathrm{~g} / \mathrm{d}$ for the unshaded treatment and $0.14 \mathrm{~g} / \mathrm{d}$ for the shaded treatment. Dropped flowers, aborted ovaries and dead roots were not included in the total plant weight, so the actual total DM production would have been somewhat greater than that given in Table 1.

\section{Development}

The rate of progress from sowing to flowering $(1 / f$, with $f$ being the number of days from sowing to $50 \%$ flowering) was not influenced by photoperiod $(P>0.05)$, but shading reduced the rate slightly $(P \leqslant 0.01)$ (Table 2$)$. No significant interaction was found between photoperiod and shading $(P>0.05)$. The average time to flowering was 41.6 days for the unshaded and 42.9 days for the shaded treatments. In all treatments, the date of $50 \%$ flowering was between the second and third harvests. Therefore the flowering data are based on 30 plants per treatment per replicate.

The rate of progress from flowering to podding $(1 /(p-f)$, with $(p-f)$ being the number of days from $50 \%$ flowering to $50 \%$ podding) was strongly influenced by photoperiod $(P \leqslant 0.01)$ and to a lesser extent by shading $(P \leqslant 0 \cdot 01)$ (Table 2$)$. The interaction effect of both factors was not significant $(P>0.05)$. The time from flowering to podding ranged from $20 \cdot 5$ days $(10.5 \mathrm{~h} / \mathrm{d}$; unshaded) to 53.5 days $(14.5 \mathrm{~h} / \mathrm{d}$; shaded).

In the unshaded treatments, the total time from sowing to podding was for the $10 \cdot 5,11 \cdot 8,13 \cdot 2$ and $14.5 \mathrm{~h} / \mathrm{d}$ photoperiods respectively $62.5,65 \cdot 0,69 \cdot 0$ and 93.5 days. The equivalent figures for the shaded treatments were $68 \cdot 5,67 \cdot 8,76 \cdot 0$ and $96 \cdot 0$ days, i.e., $3-7$ days longer. Because of the intermediate harvests, the podding data are based on 20 plants per treatment per replicate for the $10 \cdot 5,11 \cdot 8$ and $13 \cdot 2 \mathrm{~h} / \mathrm{d}$ photoperiods, and on 10 plants per treatment per replicate for the $14 \cdot 5 \mathrm{~h} / \mathrm{d}$ photoperiod.

Table 1. Mean dry weight ( $g$ ) per plant under different photoperiods and in the unshaded (Unsh.) and shaded (Sh.) treatments

\begin{tabular}{|c|c|c|c|c|c|c|c|c|}
\hline \multirow[b]{2}{*}{$\begin{array}{l}\text { Time } \\
\text { (DAS) }\end{array}$} & \multicolumn{5}{|c|}{ Photoperiod (h/d) } & \multicolumn{3}{|c|}{ Shading treatment } \\
\hline & $10 \cdot 5$ & $11 \cdot 8$ & $13 \cdot 2$ & $14 \cdot 5$ & $\begin{array}{c}\text { S.E. } \\
(3 \text { D.F. })\end{array}$ & Unsh. & Sh. & $\begin{array}{c}\text { S.E. } \\
(4 \text { D.F. })\end{array}$ \\
\hline 22 & $1 \cdot 0$ & $1 \cdot 0$ & 0.9 & $1 \cdot 0$ & $0 \cdot 04$ & $1 \cdot 1$ & 0.9 & 0.05 \\
\hline 36 & $2 \cdot 5$ & $2 \cdot 6$ & $2 \cdot 6$ & $2 \cdot 8$ & $0 \cdot 14$ & $3 \cdot 1$ & $2 \cdot 2$ & 0.09 \\
\hline 50 & $5 \cdot 6$ & $5 \cdot 2$ & $5 \cdot 5$ & $5 \cdot 8$ & $0 \cdot 22$ & $6 \cdot 8$ & $4 \cdot 3$ & $0 \cdot 12$ \\
\hline 64 & 8.9 & $9 \cdot 4$ & $9 \cdot 7$ & $9 \cdot 8$ & $0 \cdot 39$ & 11.8 & $7 \cdot 1$ & 0.35 \\
\hline 78 & $12 \cdot 4$ & $12 \cdot 2$ & $13 \cdot 7$ & $14 \cdot 2$ & $0 \cdot 37$ & $16 \cdot 2$ & $10 \cdot 0$ & $0 \cdot 13$ \\
\hline 92 & $14 \cdot 5$ & $15 \cdot 4$ & $17 \cdot 0$ & $17 \cdot 3$ & 0.88 & $20 \cdot 7$ & $11 \cdot 3$ & 0.90 \\
\hline 106 & $17 \cdot 8$ & $18 \cdot 0$ & $20 \cdot 5$ & 21.9 & $0 \cdot 30$ & $24 \cdot 6$ & $14 \cdot 6$ & 0.54 \\
\hline 120 & $19 \cdot 5$ & $21 \cdot 0$ & $23 \cdot 3$ & $24 \cdot 4$ & $1 \cdot 12$ & $27 \cdot 8$ & $16 \cdot 4$ & $0 \cdot 50$ \\
\hline
\end{tabular}


Table 2. Rates $(1 / d)$ of progress from sowing to flowering $(1 / f)$ and from flowering to podding $(1 /(p-f))$ in the unshaded (Unsh.) and shaded (Sh.) treatments under constant photoperiods of 10.5, 11.8, 13.2 and 14.5 h/d

\begin{tabular}{|c|c|c|c|c|c|c|}
\hline \multirow[b]{2}{*}{ Photoperiod (h/d) } & \multicolumn{3}{|c|}{$1 / f$} & \multicolumn{3}{|c|}{$1 /(p-f)$} \\
\hline & Unsh. & Sh. & Mean & Unsh. & Sh. & Mean \\
\hline $10 \cdot 5$ & $0 \cdot 0238$ & $0 \cdot 0230$ & 0.0234 & $0 \cdot 0488$ & 0.0403 & $0 \cdot 0445$ \\
\hline 11.8 & $0 \cdot 0238$ & $0 \cdot 0233$ & 0.0235 & $0 \cdot 0438$ & $0 \cdot 0408$ & $0 \cdot 0423$ \\
\hline $13 \cdot 2$ & $0 \cdot 0244$ & $0 \cdot 0234$ & $0 \cdot 0239$ & $0 \cdot 0357$ & 0.0301 & $0 \cdot 0329$ \\
\hline $14 \cdot 5$ & $0 \cdot 0241$ & $0 \cdot 0235$ & $0 \cdot 0238$ & $0 \cdot 0193$ & 0.0187 & $0 \cdot 0190$ \\
\hline Mean & $0 \cdot 0240$ & $0 \cdot 0233$ & $0 \cdot 0237$ & $0 \cdot 0369$ & $0 \cdot 0325$ & $0 \cdot 0347$ \\
\hline \multicolumn{7}{|l|}{ S.E.: } \\
\hline Shading effect (4 D.F.) & & $0 \cdot 00010$ & & & $0 \cdot 00068$ & \\
\hline Photoperiod effect (3 D.F.) & & $0 \cdot 00011$ & & & 0.00148 & \\
\hline Shading $\times$ photoperiod (4 D.F.) & & $0 \cdot 00018$ & & & 0.00177 & \\
\hline $\begin{array}{l}\text { Shading } \times \text { photoperiod (same } \\
\text { photoperiod level) }(4 \text { D.F. })\end{array}$ & & $0 \cdot 00019$ & & & $0 \cdot 00136$ & \\
\hline
\end{tabular}

Table 3. Total number of flowers opening per plant between the onset of flowering and the onset of podding and the number of flowers opening per day in this period in the unshaded (Unsh.) and shaded (Sh.) treatments under constant photoperiods of $10 \cdot 5,11 \cdot 8,13 \cdot 2$ and $14 \cdot 5 \mathrm{~h} / \mathrm{d}$

\begin{tabular}{|c|c|c|c|c|c|c|}
\hline \multirow[b]{2}{*}{ Photoperiod (h/d) } & \multicolumn{3}{|c|}{ Total number of flowers } & \multicolumn{3}{|c|}{ Number of flowers per day } \\
\hline & Unsh. & Sh. & Mean & Unsh. & Sh. & Mean \\
\hline $10 \cdot 5$ & 69 & 60 & 64 & $3 \cdot 05$ & $2 \cdot 50$ & $2 \cdot 78$ \\
\hline $11 \cdot 8$ & 67 & 62 & 64 & $3 \cdot 10$ & $2 \cdot 55$ & $2 \cdot 83$ \\
\hline $13 \cdot 2$ & 128 & 132 & 130 & $4 \cdot 25$ & $3 \cdot 75$ & $4 \cdot 00$ \\
\hline $14 \cdot 5$ & 251 & 207 & 229 & $4 \cdot 80$ & 3.65 & $4 \cdot 23$ \\
\hline Mean & 129 & 115 & 122 & $3 \cdot 80$ & $3 \cdot 11$ & $3 \cdot 46$ \\
\hline \multicolumn{7}{|l|}{ S.E.: } \\
\hline Shading effect (4 D.F.) & & $4 \cdot 4$ & & & $0 \cdot 088$ & \\
\hline Photoperiod effect (3 D.F.) & & $3 \cdot 9$ & & & 0.059 & \\
\hline Shading $\times$ photoperiod (4 D.F.) & & $7 \cdot 3$ & & & $0 \cdot 138$ & \\
\hline $\begin{array}{l}\text { Shading } \times \text { photoperiod (same } \\
\text { photoperiod level) }(4 \text { D.F. })\end{array}$ & & $8 \cdot 8$ & & & $0 \cdot 176$ & \\
\hline
\end{tabular}

The number of flowers per plant between the onset of flowering and the onset of podding ranged from 60 to 251 and increased with photoperiod $(P \leqslant 0 \cdot 001)$ (Table 3). This effect is partly attributable to the longer interval between flowering and podding under longer photoperiods. However, the number of flowers produced per day was also influenced by photoperiod $(P \leqslant 0.001)$. It was less under 10.5 and $11.8 \mathrm{~h} / \mathrm{d}$ than under 13.2 and $14.5 \mathrm{~h} / \mathrm{d}$ photoperiods (Table 3 ). Shading also influenced the number of flowers produced per day, which was less in the shaded plants $(P \leqslant 0 \cdot 01)$.

The number of leaves and the leaf area were significantly $(P \leqslant 0.05)$ influenced by shading from the second harvest (36 DAS) onwards (Fig. 1). Leaf number was significantly $(P \leqslant 0 \cdot 05)$ influenced by photoperiod from the third harvest (50 DAS) onwards, leaf area from the fourth (64 DAS). Significant $(P \leqslant 0.05)$ interaction effects between photoperiod and shading were found at the last two harvests (106 and 120 DAS) only. The mean number of pods was significantly $(P \leqslant 0.01)$ fewer in the shaded treatments from 78 DAS onwards. Photoperiod effects and interaction effects between photoperiod and shading were only significant $(P \leqslant 0.05)$ at the harvests at 78 and 92 DAS. At the final harvest there was no significant difference $(P>0 \cdot 05)$ between the photoperiod treatments in the mean number of pods per plant. Figure 1 shows that the rapid increase in the number of pods per plant in the first few weeks after the onset of podding coincides with a slowing down of the rate of increase in the number of leaves per plant.

\section{Dry matter partitioning}

The photoperiod effects on partitioning of the DM increase before the onset of podding and the interaction effects between photoperiod and shading 

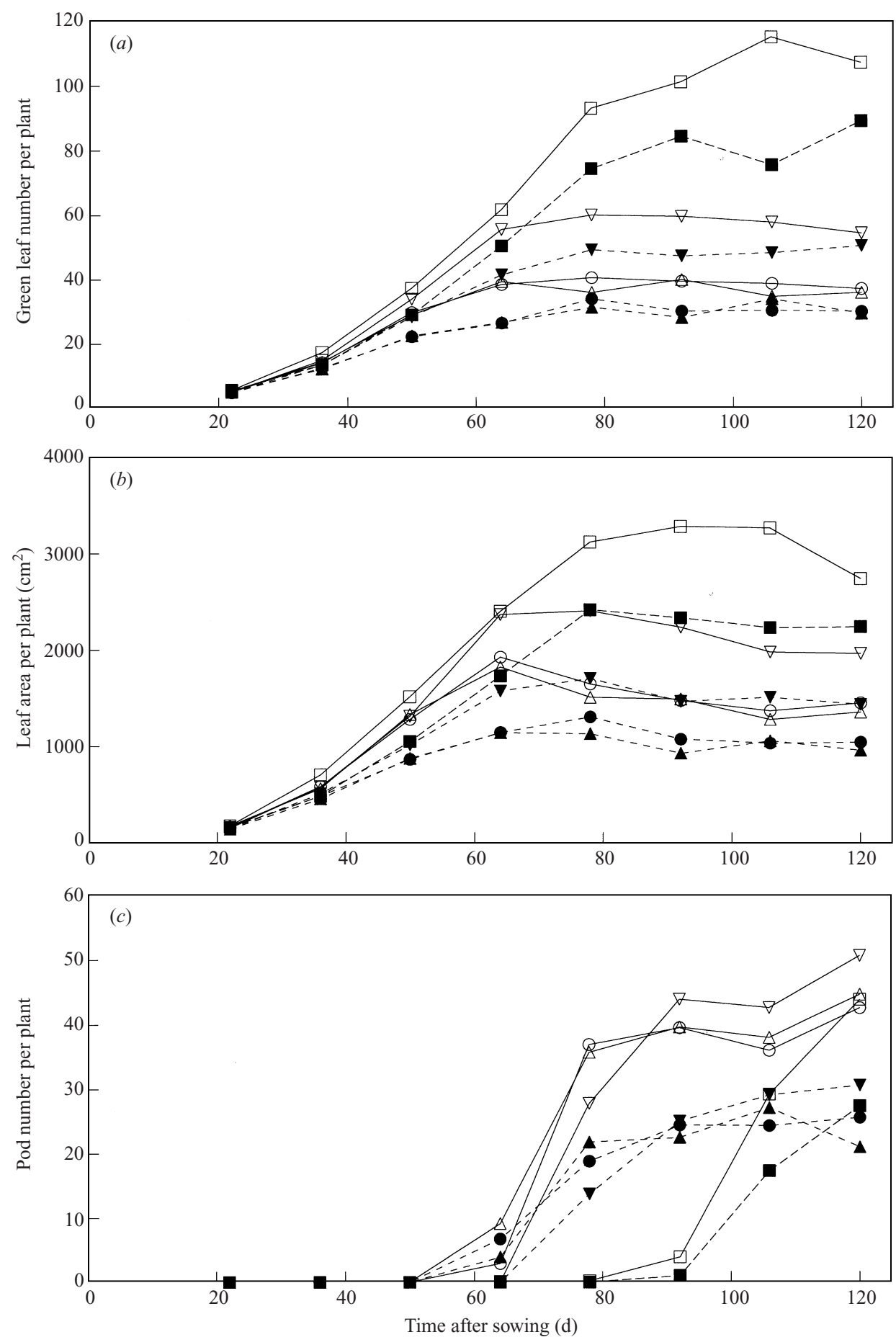

Fig. 1. Mean $(a)$ green leaf number, $(b)$ leaf area, and $(c)$ pod number per plant against time after sowing for plants grown in the unshaded (open symbols) and shaded (closed symbols) treatments under constant photoperiods of $10 \cdot 5(\triangle, \boldsymbol{\Delta}), 11 \cdot 8$ $(\bigcirc, \bullet), 13 \cdot 2(\nabla, \nabla)$, and $14 \cdot 5(\square, \boldsymbol{\square}) \mathrm{h} / \mathrm{d}$. 
Table 4. Fraction of the plant dry weight increase partitioned to different organs in the pre-podding period

\begin{tabular}{|c|c|c|c|c|c|c|}
\hline \multirow[b]{2}{*}{$\begin{array}{l}\text { Period } \\
\text { (DAS) }\end{array}$} & \multicolumn{6}{|c|}{ Fraction } \\
\hline & Roots & $\begin{array}{c}\text { Leaf } \\
\text { blades }\end{array}$ & Petioles & Stems & Pods & Total \\
\hline $0-22$ & $0 \cdot 17$ & 0.55 & $0 \cdot 17$ & $0 \cdot 11$ & $0 \cdot 00$ & $1 \cdot 00$ \\
\hline $22-36$ & $0 \cdot 22$ & $0 \cdot 51$ & $0 \cdot 18$ & $0 \cdot 08$ & $0 \cdot 00$ & $1 \cdot 00$ \\
\hline $36-50$ & 0.09 & $0 \cdot 55$ & $0 \cdot 25$ & $0 \cdot 12$ & $0 \cdot 00$ & $1 \cdot 00$ \\
\hline $50-64$ & $0 \cdot 08$ & 0.53 & $0 \cdot 25$ & $0 \cdot 12$ & $0 \cdot 02$ & $1 \cdot 00$ \\
\hline
\end{tabular}

were generally not significant $(P>0 \cdot 05)$, though partitioning to the stems tended to be somewhat greater under longer photoperiods, and partitioning to the roots somewhat less (data not shown).
Significant $(P \leqslant 0.05)$ shading effects were found during the first 3 weeks after sowing, but generally not later (data not shown). Partitioning to the leaf blades remained constant in the pre-podding period, but after 36 DAS partitioning to the roots decreased and partitioning to petioles and stems increased (Table 4).

The partitioning of the DM increase after the onset of podding was analysed using data on the $10 \cdot 5,11 \cdot 8$, and $13.2 \mathrm{~h} / \mathrm{d}$ photoperiods. Data on the $14.5 \mathrm{~h} / \mathrm{d}$ photoperiod were not used, because $50 \%$ podding occurred so much later in that treatment. Partitioning after the onset of podding was not $(P>0.05)$ influenced by photoperiod (in the range from 10.5 to $13.2 \mathrm{~h} / \mathrm{d}$ ) or by shading. The vegetative plant parts still showed some growth in the first 2 weeks after the onset of podding, but thereafter DM was reallocated to the pods (Table 5). The values in Table 5 are based on calculations including fallen (dead) plant material,

Table 5. Fraction of the plant dry weight increase partitioned to different organs after the onset of podding (based on all treatments except the $14.5 \mathrm{~h} / \mathrm{d}$ treatment). The average onset of podding was $68 \mathrm{DAS}$

\begin{tabular}{|c|c|c|c|c|c|c|}
\hline \multirow[b]{2}{*}{ Period (DAS) } & \multicolumn{6}{|c|}{ Fraction } \\
\hline & Roots & Leaf blades & Petioles & Stems & Pods & Total \\
\hline $64-78$ & 0.00 & $0 \cdot 15$ & $0 \cdot 08$ & 0.06 & 0.72 & 1.00 \\
\hline $78-92$ & -0.04 & -0.09 & $-0 \cdot 12$ & -0.02 & 1.27 & $1 \cdot 00$ \\
\hline $97-106$ & -0.09 & $-0 \cdot 12$ & $-0 \cdot 10$ & -0.04 & $1 \cdot 34$ & 1.00 \\
\hline $106-120$ & $-0 \cdot 12$ & $-0 \cdot 04$ & $-0 \cdot 13$ & -0.01 & $1 \cdot 29$ & $1 \cdot 00$ \\
\hline
\end{tabular}

Table 6. Fraction of the plant dry weight increase partitioned to different organs after the onset of podding in the $14.5 \mathrm{~h} / \mathrm{d}$ treatment. The average onset of podding was $95 \mathrm{DAS}$

\begin{tabular}{crccrrr}
\hline \hline & \multicolumn{5}{c}{ Fraction } \\
\cline { 2 - 6 } Period (DAS) & Roots & Leaf blades & Petioles & Stems & Pods & Total \\
\hline $92-106$ & $0 \cdot 08$ & $0 \cdot 12$ & $0 \cdot 00$ & $0 \cdot 06$ & $0 \cdot 74$ & $1 \cdot 00$ \\
$106-120$ & $-0 \cdot 18$ & $-0 \cdot 26$ & -0.07 & -0.03 & 1.54 & $1 \cdot 00$ \\
\hline \hline
\end{tabular}

Table 7. Mean pod dry weight (g) per plant under different photoperiods and in the unshaded (Unsh.) and shaded (Sh.) treatments

\begin{tabular}{|c|c|c|c|c|c|c|c|c|}
\hline \multirow[b]{2}{*}{$\begin{array}{l}\text { Time } \\
\text { (DAS) }\end{array}$} & \multicolumn{5}{|c|}{ Photoperiod (h/d) } & \multicolumn{3}{|c|}{ Shading treatment } \\
\hline & $10 \cdot 5$ & $11 \cdot 8$ & $13 \cdot 2$ & $14 \cdot 5$ & $\begin{array}{c}\text { S.E. } \\
\text { (3 D.F.) }\end{array}$ & Unsh. & Sh. & $\begin{array}{c}\text { S.E } \\
(4 \text { D.F. })\end{array}$ \\
\hline 22 & $0 \cdot 0$ & $0 \cdot 0$ & $0 \cdot 0$ & $0 \cdot 0$ & $0 \cdot 00$ & $0 \cdot 0$ & $0 \cdot 0$ & $0 \cdot 00$ \\
\hline 36 & $0 \cdot 0$ & $0 \cdot 0$ & $0 \cdot 0$ & $0 \cdot 0$ & $0 \cdot 00$ & $0 \cdot 0$ & $0 \cdot 0$ & $0 \cdot 00$ \\
\hline 50 & $0 \cdot 0$ & $0 \cdot 0$ & $0 \cdot 0$ & $0 \cdot 0$ & 0.00 & $0 \cdot 0$ & $0 \cdot 0$ & $0 \cdot 00$ \\
\hline 64 & $0 \cdot 1$ & $0 \cdot 1$ & $0 \cdot 0$ & $0 \cdot 0$ & 0.06 & $0 \cdot 1$ & $0 \cdot 1$ & $0 \cdot 01$ \\
\hline 78 & $2 \cdot 9$ & $1 \cdot 8$ & $1 \cdot 1$ & $0 \cdot 0$ & $0 \cdot 35$ & $2 \cdot 2$ & $0 \cdot 7$ & $0 \cdot 34$ \\
\hline 92 & $4 \cdot 8$ & $5 \cdot 1$ & $4 \cdot 1$ & $0 \cdot 1$ & $0 \cdot 44$ & $5 \cdot 0$ & $2 \cdot 1$ & $0 \cdot 29$ \\
\hline 106 & $8 \cdot 4$ & $7 \cdot 7$ & $7 \cdot 9$ & $2 \cdot 0$ & 0.62 & $8 \cdot 4$ & $4 \cdot 4$ & $0 \cdot 40$ \\
\hline 120 & $10 \cdot 1$ & $11 \cdot 0$ & $11 \cdot 2$ & $5 \cdot 3$ & 0.59 & $12 \cdot 5$ & $6 \cdot 3$ & $0 \cdot 38$ \\
\hline
\end{tabular}


thus the negative values are due to reallocation. In the $14.5 \mathrm{~h} / \mathrm{d}$ treatment, partitioning after the onset of podding showed the same trend (Table 6) as in the other photoperiods. At the final harvest, the pod dry weight per plant in the shaded treatments was half that in the unshaded treatments (Table 7). Pod dry weights under $10.5,11.8$ and $13.2 \mathrm{~h} / \mathrm{d}$ photoperiods were very similar, but they were much lower under $14.5 \mathrm{~h} / \mathrm{d}$.

\section{DISCUSSION}

Interaction between growth and development

In this study, shading ( $42 \%$ light reduction) reduced plant DM production by $41 \%$ (Table 1 ). This was accompanied by a slight decrease in the rate of progress from sowing to flowering $(3 \%)$ and the rate of progress from flowering to podding $(12 \%)$ (Table 2 ). Together, these results suggest that there may be some interaction between growth and development in bambara groundnut, but that the effect is small. The results also imply that the onset of flowering and podding in bambara groundnut grown as an intercrop and shaded by taller cereals will not be very different from that in sole-cropped bambara groundnut.

The finding that photoperiod generally did not significantly affect total plant growth, is in accordance with that of Linnemann et al. (1995), who found no photoperiod influence on above ground DM accumulation in bambara groundnut selection 'Ankpa4' from Nigeria and only a slight influence in 'Tiga Nicuru' from Mali. However, in a study in which the time to podding differed more between photoperiod treatments and plants were allowed to grow for longer (183 days), plant weights (excluding roots) at final harvest were greater under long photoperiods (Brink, 1998).

\section{Photoperiod and dry matter partitioning}

The findings of this study confirm that the onset of podding coincides with a major shift in the assimilate distribution, which becomes directed mainly towards pod growth. As photoperiod has a strong influence on the time of onset of podding, the indirect effect of photoperiod on DM partitioning is obvious. Direct photoperiod effects on DM partitioning before the onset of podding were not significant, but partitioning to the stems tended to be greater under longer photoperiods. This tendency is in agreement with earlier findings that the percentage of above-ground DM partitioned to the leaf blades is greater under short photoperiods and the percentage partitioned to the stem parts less (Linnemann et al. 1995). A direct effect of photoperiod on DM partitioning after the onset of podding was not found, which is in contrast with earlier findings in bambara groundnut (Linnemann et al. 1995) and soyabean (Cure et al. 1982; Morandi et al. 1988). However, it confirms the findings of Brink (1998), who found that seed yield in bambara groundnut is strongly related to the time to podding and not to the photoperiod during the podfilling phase.

\section{Determinacy}

Loomis \& Connor (1992) distinguish determinate, indeterminate and facultative determinate crops. In determinate crops, vegetative growth ceases at flowering, because the shoot's apical meristem is converted to the reproductive structure. In indeterminate crops, vegetative growth may continue for weeks or months after the start of flowering. In such crops, the apical meristem continues to produce leaves, while flowers are formed from axillary meristems. The advantage of indeterminacy is that prolonged flowering enables the plant to compensate for loss of flowers or seed as a result of temporary adverse conditions. Under certain conditions, reproductive growth in some indeterminate plants monopolizes all assimilates and apical activity ceases, resulting in facultative determinacy (Loomis \& Connor 1992). In the present study it was found that the onset of podding in bambara groundnut coincides with a slowing down of the rate of leaf appearance (Fig. 1). This suggests that though bambara groundnut is an indeterminate plant (leaf formation is not influenced by the onset of flowering), the onset of podding leads to facultative determinacy.

Table 8. Means and standard errors of the times from sowing to podding in the different treatment combinations as determined by direct podding observations (method 1) and by linear regression of the pod weights at intermediate and final harvests against time (method 2)

\begin{tabular}{|c|c|c|c|c|}
\hline \multirow{2}{*}{$\begin{array}{l}\text { Photoperiod } \\
\text { (h/d) }\end{array}$} & \multicolumn{2}{|c|}{ Non-shaded } & \multicolumn{2}{|c|}{ Shaded } \\
\hline & Method 1 & Method 2 & Method 1 & Method 2 \\
\hline $10 \cdot 5$ & $62 \cdot 5 \pm 1 \cdot 5$ & $61 \cdot 5 \pm 3 \cdot 0$ & $68 \cdot 5 \pm 2 \cdot 5$ & $65 \cdot 7 \pm 0 \cdot 0$ \\
\hline $11 \cdot 8$ & $65 \cdot 0 \pm 3 \cdot 0$ & $65 \cdot 6 \pm 2 \cdot 5$ & $67 \cdot 5 \pm 1 \cdot 5$ & $66 \cdot 7 \pm 0 \cdot 1$ \\
\hline $13 \cdot 2$ & $69 \cdot 0 \pm 1 \cdot 0$ & $72 \cdot 1 \pm 0.9$ & $76 \cdot 0 \pm 0 \cdot 0$ & $77 \cdot 0 \pm 0 \cdot 4$ \\
\hline $14 \cdot 5$ & $93 \cdot 5 \pm 2 \cdot 5$ & $92 \cdot 4 \pm 1 \cdot 8$ & $96 \cdot 0 \pm 1 \cdot 0$ & $93 \cdot 7 \pm 0 \cdot 9$ \\
\hline
\end{tabular}




\section{Podding observations}

In studies by Linnemann \& Craufurd (1994) and Linnemann et al. (1995), the onset of flowering in bambara groundnut was determined in the same way as in the present study, but the onset of podding was not. In the present study, podding was observed directly, whereas Linnemann \& Craufurd (1994) and Linnemann et al. (1995) determined the onset of podding through linear regression of pod weights at different harvests against time. Because intermediate harvests were carried out in the present study, it was possible to compare the two methods. The results obtained by the different methods do not differ much (Table 8), which implies that both methods are equally valid. An important advantage of observing podding directly is that far fewer plants are required. However, the method cannot be used on bambara groundnut selections that form pods underground or when plants are earthed-up before the onset of podding.

The author wishes to thank J. J. M. Belde, A. F. Blokzijl, T. H. J. Damen, C. B. M. Pillen, J. C. M. van der Pal, J. H. Scholten and T. Stoker for their assistance during the experiment, S. K. Karikari and M. A. Muilenburg for supplying seed and Rhizobium respectively, and R. Rabbinge, J. Vos, M. Wessel and E. Westphal for valuable comments on the manuscript. The study was carried out in the framework of the international research project 'Evaluating the potential for bambara groundnut as a food crop in semi-arid Africa', supported by the Life Sciences and Technologies for Developing Countries Programme of the European Union.

\section{REFERENCES}

AnON. (1989). Praktijkboek Plantenbelichting. Deel 2: Belichtingstechnieken. Eindhoven: Philips Licht.

BRINK, M. (1997). Rates of progress towards flowering and podding in bambara groundnut (Vigna subterranea) as a function of temperature and photoperiod. Annals of Botany 80, 505-513.

BRINK, M. (1998). Matching crops and environments: quantifying photothermal influences on reproductive development in bambara groundnut (Vigna subterranea $(L$.) Verdc.). PhD thesis, Wageningen Agricultural University.

Cure, J. D., Patterson, R. P., Raper JR, C. D. \& Jackson, W. A. (1982). Assimilate distribution in soybeans as affected by photoperiod during seed development. Crop Science 22, 1245-1250.

Hodges, T. (1991). Modeling and programming philosophies. In Predicting Crop Phenology (Ed. T. Hodges), pp. 101-114. Boca Raton: CRC Press.

LinnemanN, A. R. (1994). Photothermal regulation of phenological development and growth in bambara groundnut (Vigna subterranea (L.) Verdc.). PhD thesis, Wageningen Agricultural University.

Linnemann, A. R. \& Azam-Ali, S. N. (1993). Bambara groundnut (Vigna subterranea). In Pulses and Vegetables (Ed. J. T. Williams), pp. 13-58. London: Chapman and Hall.

Linnemann, A. R. \& Craufurd, P. Q. (1994). Effects of temperature and photoperiod on phenological development in three genotypes of bambara groundnut (Vigna subterranea). Annals of Botany 74, 675-681.

Linnemann, A. R., Westphal, E. \& Wessel, M. (1995). Photoperiod regulation of development and growth in bambara groundnut (Vigna subterranea). Field Crops Research 40, 39-47.

LoOMIs, R. S. \& ConNor, D. J. (1992). Crop Ecology: Productivity and Management in Agricultural Systems. Cambridge: Cambridge University Press.

Morandi, E. N., Casano, L. M. \& Reggiardo, L. M. (1988). Post-flowering photoperiodic effect on reproductive efficiency and seed growth in soybean. Field Crops Research 18, 227-241.

Payne, R. W., Lane, P. W., Digby, P. G. N., Harding, S. A., Leech, P. K., Morgan, G. W., Todd, A. D., Thompson, R., Tunnicliffe Wilson, G., Welham, S. J. \& White, R. P. (1993). Genstat 5 Release 3 Reference Manual. Oxford: Clarendon Press.

Sinclair, T. R., Kitani, S., Hinson, K., Bruniard, J. \& HorIE, T. (1991). Soybean flowering date: linear and logistic models based on temperature and photoperiod. Crop Science 31, 786-790.

Summerfield, R. J., Roberts, E. H., Ellis, R. H. \& Lawn, R. J. (1991). Towards the reliable prediction of time to flowering in six annual crops. I. The development of simple models for fluctuating field environments. Experimental Agriculture 27, 11-31. 